\title{
Effects of growth hormone therapeutic supplementation on hematopoietic stem/progenitor cells in children with growth hormone deficiency: focus on proliferation and differentiation capabilities
}

\author{
M. P. Kawa ${ }^{1}$ - I. Stecewicz ${ }^{2}$ K. Piecyk ${ }^{1}$ - E. Pius-Sadowska ${ }^{1}$ - E. Paczkowska ${ }^{1}$ \\ D. Rogińska ${ }^{1}$ - A. Sobuś ${ }^{1}$ K. Kuczkowska ${ }^{1}$ - E. Gawrych ${ }^{3}$ - E. Petriczko ${ }^{2}$. \\ M. Walczak ${ }^{2} \cdot$ B. Machaliński ${ }^{1}$
}

Received: 27 October 2014/Accepted: 30 March 2015/Published online: 29 April 2015

(c) The Author(s) 2015. This article is published with open access at Springerlink.com

\begin{abstract}
We investigated the direct effects of growth hormone (GH) replacement therapy (GH-RT) on hematopoiesis in children with GH deficiency (GHD) with the special emphasis on proliferation and cell cycle regulation. Peripheral blood (PB) was collected from sixty control individuals and forty GHD children before GH-RT and in 3rd and 6th month of GH-RT to measure hematological parameters and isolate $\mathrm{CD} 34^{+}$-enriched hematopoietic progenitor cells (HPCs). Selected parameters of $\mathrm{PB}$ were analyzed by hematological analyzer. Moreover, collected HPCs were used to analyze GH receptor (GHR) and IGF1 expression, clonogenicity, and cell cycle activity. Finally, global gene expression profile of collected HPCs was analyzed using genome-wide RNA microarrays. GHD resulted in a decrease in several hematological parameters related to RBCs and significantly diminished clonogenicity of erythroid progenies. In contrast, GH-RT stimulated increases in clonogenic growth of erythroid lineage and RBC counts as well as significant up-regulation of cell cyclepropagating genes, including MAP2K1, cyclins DI/E1, $P C N A$, and $I G F 1$. Likewise, GH-RT significantly modified
\end{abstract}

Electronic supplementary material The online version of this article (doi:10.1007/s12020-015-0591-0) contains supplementary material, which is available to authorized users.

B. Machaliński

machalin@pum.edu.pl

1 Department of General Pathology, Pomeranian Medical University, Szczecin, Poland

2 Department of Pediatrics, Endocrinology, Diabetology, Metabolic Diseases and Cardiology of the Developmental Age, Pomeranian Medical University, Szczecin, Poland

3 Department of Pediatric and Oncological Surgery, Pomeranian Medical University, Szczecin, Poland
GHR expression in isolated HPCs and augmented systemic IGF1 levels. Global gene expression analysis revealed significantly higher expression of genes associated with cell cycle, proliferation, and differentiation in HPCs from GH-treated subjects. (i) GH-RT significantly augments cell cycle progression in HPCs and increases clonogenicity of erythroid progenitors; (ii) GHR expression in HPCs is modulated by GH status; (iii) molecular mechanisms by which GH influences hematopoiesis might provide a basis for designing therapeutic interventions for hematological complications related to GHD.

Keywords Hematopoietic stem/progenitor cells . Hematopoiesis · Growth hormone deficiency - Growth hormone deficiency in children

\section{Introduction}

Growth hormone $(\mathrm{GH})$ is a pleiotropic hormone important for modulation of physiological processes [1]. Importantly, GH exerts its anabolic effects largely indirectly via stimulation of insulin-like growth factor-1 (IGF1) production. However, acting in autocrine/paracrine manner, GH binds to the specific receptor (GHR), which induces intracellular signaling pathways leading to differential gene expression [1]. The classical examples of IGF1-independent actions mediated through GHR include ovarian preantral follicle development [2] or activation of chondrocyte stem cells for chondrocyte generation at bone growth plate [3]. Similarly, in vitro studies indicate that neural stem cell activation by GH does not require IGF1 [4].

$\mathrm{GH}$ is also a potent modulator of hematopoietic system, which has been described in numerous experimental studies. GH binds to GHR expressed on hematopoietic/immune 
cells and regulates their proliferation and differentiation [5, 6]. GH was shown to augment in vitro erythropoiesis [7], granulopoiesis [8], and lymphopoiesis [9]. Likewise, supplementation with recombinant human $\mathrm{GH}(\mathrm{rhGH})$ was reported to reverse the age-induced hypocellularity of bone marrow in old rats [10]. rhGH administered to mice or nonhuman primates following lethal irradiation accelerated their hematopoietic recovery [11].

Isolated GHD (IGHD) is a rare disease and its final diagnosis is classically based on auxological and laboratory criteria, including short stature, reduced growth velocity, delayed bone age, and low GH responses to at least two pharmacological stimuli [12]. GHD patients exhibit numerous abnormalities in the hematological parameters of peripheral blood (PB), including microcytosis, anisocytosis, and poikilocytosis [13]. Furthermore, GHD patients commonly suffer from certain types of anemia, which are described in the literature as "IGHD-related anemia" [14]. The number of white blood cells is often reduced [15]. It was demonstrated that the metabolic abnormalities typical of GHD may be reversed by $\mathrm{GH}$ replacement therapy (GHRT) [16]. However, the exogenous administration of rhGH, which has paracrine functions, does not necessarily mimic the physiological activity of $\mathrm{GH}$, and the precise biological activity of rhGH requires further study. Data regarding rhGH-induced modulation of hematopoiesis during GH-RT are very limited, and only a few studies have evaluated the relationship between GHD and hematological parameters in children [17-20].

Therefore, we assessed the clinical outcomes of inappropriate $\mathrm{GH}$ signaling in $\mathrm{CD}_{3} 4^{+}$-enriched hematopoietic stem and progenitor cells collected from IGHD children. In addition, we evaluated the effects of 6-month GH-RT on proliferation and differentiation of $\mathrm{CD}_{3} 4^{+}$cells and recovery of PB parameters.

\section{Materials and methods}

\section{Subjects}

We enrolled 40 children with severe IGHD, who were diagnosed according to the clinical criteria [12]. rhGH therapy was administered by subcutaneous injection at $0.031 \mathrm{mg} / \mathrm{kg} / \mathrm{d}$. None of the patients suffered from diabetes insipidus, chromosomal abnormalities, dysmorphic syndromes, intestinal malabsorption, other chronic diseases, or acquired GHD, as confirmed by a full clinical and laboratory evaluation. 60 children of similar ages, who did not differ significantly in terms of puberty and bone age, constituted the control group. All procedures were approved by local ethics committee, and informed consent was provided for each patient.

\section{Laboratory measurements and cell isolation}

PB samples were collected at the moment of GHD diagnosis and after 3 and 6 months of GH-RT. We determined hematological and hormonal parameters and isolated $\mathrm{CD} 34^{+}$-enriched hematopoietic progenitor cells (HPCs). The selected hematological parameters were evaluated using cell analyzer (Cell Dyn 3000, Abbott Diagnostics). The mononuclear cell fraction was isolated by density gradient centrifugation and depleted of adherent and $\mathrm{T}$ cells. This fraction was next enriched for $\mathrm{CD}^{+} 4^{+}$cells using the CD34 MicroBead Kit (Miltenyi Biotech, USA) according to the manufacturer's protocol.

\section{RNA isolation and gene expression analysis}

Total mRNA was isolated from HPCs using the RNeasy Mini Kit (Qiagen, USA). Subsequently, mRNA was reverse transcribed using the First Strand cDNA Synthesis Kit (Fermentas International Inc., Canada). Quantitative assessment of GHR, MAP2K1, Cyclin D1, Cyclin E1, $P C N A$, and IGF1 mRNA levels was performed using realtime QRT-PCR carried out on a Bio-Rad CFX96 RealTime PCR Detection System (Bio-Rad Inc., USA). The 25 $\mu \mathrm{L}$ reaction mixture contained $12.5 \mu \mathrm{L}$ of SYBR Green PCR Master Mix, $10 \mathrm{ng}$ of cDNA template, and one pair of the primers listed in Supplementary Table 1. The relative quantification value of the target gene was normalized to the endogenous control gene (BMG) and expressed as $2^{\Delta \mathrm{Ct}}$, where $\Delta \mathrm{Ct}=[\mathrm{Ct}$ of endogenous control gene $]-[\mathrm{Ct}$ of target gene].

\section{Flow cytometry}

CD34 ${ }^{+}$HPCs and lymphocytes were analyzed with respect to the GHR expression. Briefly, erythrocytes in PB samples were lysed using BD PharmLyse Lysing Solution (BD Biosciences) for $15 \mathrm{~min}$ to obtain nucleated cells (NC). A total of $1 \times 10^{6} \mathrm{NCs}$ were incubated with mouse anti-human fluorochrome-conjugated monoclonal antibodies against specific antigens, including GHR, CD34, and CD45 (all from BD Biosciences) and analyzed by flow cytometry (LSRII, BD Biosciences). At least $0.5 \times 10^{6}$ cells with the appropriate ratio of forward scatter to side scatter were acquired for the analysis.

\section{Clonogenic in vitro assays}

$\mathrm{CD}^{+}{ }^{+}$HPCs were evaluated using in vitro clonogenic assays. Briefly, $2 \times 10^{4}$ cells were resuspended in $0.4 \mathrm{~mL}$ of RPMI-1640 medium (Sigma Aldrich, USA) and mixed with $1.8 \mathrm{~mL}$ of MethoCult HCC-4230 (StemCell Technologies Inc., Canada) supplemented with 
L-glutamine and antibiotics. To stimulate granulocytemacrophage colony-forming units (CFU-GM), IL-3 (20 U/mL), SCF $(10 \mathrm{ng} / \mathrm{mL})$, and GM-CSF $(5 \mathrm{ng} / \mathrm{mL})$ were used. EPO $(5 \mathrm{U} / \mathrm{mL})$ and $\mathrm{SCF}(10 \mathrm{ng} / \mathrm{mL})$ were used for induction of erythrocyte burst-forming units (BFU-E). IL-7 (5 ng/mL) and SCF (10 ng/mL) (all from $R \& D$ System) were used for induction of B-lymphocyte colony-forming units (CFU-B lymph). Each clonogenic test was performed in quadruplicate.

\section{Cell cycle analysis}

Cell cycle progression in CD34 ${ }^{+}$HPCs was analyzed using the APO-Direct kit (BD Biosciences) according to the manufacturer's instructions.

\section{ELISA}

The systemic levels of IGF1 were measured using commercially available, high-sensitivity ELISA Quantikine human immunoassay kit (R\&D Systems, USA) according to the manufacturer's instructions.

\section{RNA isolation and Affymetrix GeneChip microarray and data analysis}

Total RNA was isolated from $\mathrm{CD}_{4} 4^{+}$HPCs using RNeasy Mini Kit (Qiagen, USA). RNA was isolated from $\mathrm{CD} 34^{+}$cells of five GH-treated patients, the same at baseline, and in 3rd and 6th months of treatment, and of five control subjects, and was pooled to generate the final RNA sample representing a particular group in subsequent experimental procedures. Sense-strand cDNA generated from total RNA using an Ambion WT Expression Kit (Life Technologies, UK) was fragmented and labeled using the GeneChipH WT Terminal Labeling Kit (Affymetrix, USA) and hybridized onto an Affymetrix WT Array Strip. Hybridization as well as subsequent fluidics and scanning steps were performed using an Affymetrix GeneAtlasTM system (Affymetrix). Differences in the expression of the chosen genes and Gene Ontology (GO) terms were analyzed in the $\mathrm{R}$ programming environment using Bioconductor packages.

\section{Statistical methods}

Differences in the values of the quantitative parameters were compared between groups by unpaired Student's $t$ test with Welch's correction; for nonparametric tests, values were compared using the Mann-Whitney test. A $P$ value of $<0.05$ was considered statistically significant.

\section{Results}

\section{Characteristics of the clinical parameters}

The characteristics of the subjects enrolled in the study are summarized in Table S2.

\section{Changes in the hematological parameters of patients with GHD}

Selected PB parameters were measured at diagnosis and after 6 months of GH-RT as well in the control group (Table 1). Subjects were divided into two groups, 4-10 ("younger") and 11-17 ("older") years of age, due to common age-dependent changes in hematological parameters. We detected significantly decreased values of RBCs, HGB, and HCT, regardless of age, in untreated GHD patients compared to controls. Similarly, the GHD patients (11-17 years of age) exhibited significantly smaller $\mathrm{MCH}$ values, indicating a hypochromic state of RBCs. Moreover, GHD patients (4-10 years of age) exhibited significantly diminished MCV values, indicating microcytosis. In the same manner, we compared GHD patients before therapy and after 6 months of GH-RT and noticed a significant increase of RBCs, HGB, HCT, and MCV values after GH-RT, regardless of age. Finally, a statistically significant increase in $\mathrm{MCH}$ value was observed; however, this difference was only detected in younger GH-treated children. Of note, we were not able to detect any significant changes in platelets or WBCs in any of the analyzed groups. These data indicate that GH-RT could influence the morphological and functional changes in cells of erythropoietic lineage in GHD patients.

\section{GHR is expressed at the mRNA level in HPCs from GHD patients and is modulated by GH therapy}

Cells from all examined groups expressed GHR mRNA, We observed a strong around $300 \%$ up-regulation of $G H R$ mRNA in $\mathrm{CD}_{3} 4^{+}$HPCs collected after 6 months of GHRT $(P<0.001$; Fig. 1$)$ and its brisk $50 \%$ up-regulation after 3 months of GH-RT ( $P<0.05$; Fig. 1$)$, compared to GHD patients before therapy. These data indicate that GHR expression could be influenced by GH therapy; thus, it may regulate GH-dependent effects in HPCs.

\section{The number of $\mathrm{GHR}^{+}$hematopoietic cells increases during GH-RT in GHD patients}

Next, we investigated the relationship between $\mathrm{GHR}^{+}$hematopoietic cell numbers and GH status. We simultaneously evaluated the number of $\mathrm{GHR}^{+} \mathrm{HPCs}$ and $\mathrm{GHR}^{+}$ 
Table 1 Selected blood parameters in patients recruited for the study

\begin{tabular}{|c|c|c|c|c|}
\hline Parameter & Age-matched GHD patients & $\begin{array}{l}\text { GHD_before GH therapy } \\
\text { Mean } \pm \text { SD }\end{array}$ & $\begin{array}{l}\text { GHD—6th month GH therapy } \\
\text { Mean } \pm \text { SD }\end{array}$ & $\begin{array}{l}\text { Controls } \\
\text { Mean } \pm \text { SD }\end{array}$ \\
\hline \multirow[t]{2}{*}{$\mathrm{RBC}\left(10^{6} / \mathrm{mm}^{3}\right)$} & Younger & $4,55 \pm 0.08^{\#}$ & $4.85 \pm 0.08 * *$ & $4.76 \pm 0.06$ \\
\hline & Older & $4.58 \pm 0.06^{\#}$ & $4.86 \pm 0.07 * *$ & $4.86 \pm 0.09$ \\
\hline \multirow[t]{2}{*}{ HGB (g/dl) } & Younger & $12.01 \pm 0.26^{\#}$ & $13.18 \pm 0.23 * *$ & $12.95 \pm 0.23$ \\
\hline & Older & $12.86 \pm 0.09^{\# \# \#}$ & $13.88 \pm 0.19 * * * *$ & $13.91 \pm 0.29$ \\
\hline \multirow[t]{2}{*}{$\mathrm{HCT}(\%)$} & Younger & $35.29 \pm 0.56^{\#}$ & $38.52 \pm 0.67 * * *$ & $37.26 \pm 0.66$ \\
\hline & Older & $37.60 \pm 0.43^{\# \# \#}$ & $40.60 \pm 0.56^{* * *}$ & $40.65 \pm 0.70$ \\
\hline \multirow[t]{2}{*}{$\operatorname{MCV}\left(\mathrm{mm}^{3}\right)$} & Younger & $76.99 \pm 0.58^{\# \#}$ & $79.38 \pm 0.84^{*}$ & $82.01 \pm 1.79$ \\
\hline & Older & $81.42 \pm 0.71$ & $84.04 \pm 0.84 *$ & $81.62 \pm 1.05$ \\
\hline \multirow[t]{2}{*}{$\mathrm{MCH}(\mathrm{pg})$} & Younger & $26.30 \pm 0.36$ & $27.09 \pm 0.26$ & $27.63 \pm 0.61$ \\
\hline & Older & $27.85 \pm 0.31^{\#}$ & $28.83 \pm 0.31 *$ & $28.81 \pm 0.34$ \\
\hline \multirow[t]{2}{*}{$\mathrm{MCHC}(\mathrm{g} / \mathrm{dl})$} & Younger & $34.16 \pm 0.32$ & $34.21 \pm 0.26$ & $34.30 \pm 0.44$ \\
\hline & Older & $34.25 \pm 0.26$ & $34.08 \pm 0.23$ & $34.06 \pm 0.30$ \\
\hline \multirow[t]{2}{*}{ PLT $\left(10^{5} / \mathrm{mm}^{3}\right)$} & Younger & $322.9 \pm 11.89$ & $313.8 \pm 23.34$ & $279.6 \pm 17.30$ \\
\hline & Older & $285.5 \pm 9.68$ & $260.9 \pm 8.35$ & $254.3 \pm 15.14$ \\
\hline \multirow[t]{2}{*}{ WBC $\left(10^{3} / \mathrm{mm}^{3}\right)$} & Younger & $7.81 \pm 0.51$ & $7.853 \pm 0.58$ & $8.21 \pm 0.68$ \\
\hline & Older & $6.386 \pm 0.25$ & $6.130 \pm 0.23$ & $7.131 \pm 0.39$ \\
\hline
\end{tabular}

$* P<0.05$; ** $P<0.01$; *** $P<0.001$; **** $P<0.0001$ vs. values of GHD patients before therapy

${ }^{\#} P<0.05 ;{ }^{\#} P<0.01 ;{ }^{\# \# \#} P<0.001$ vs. controls

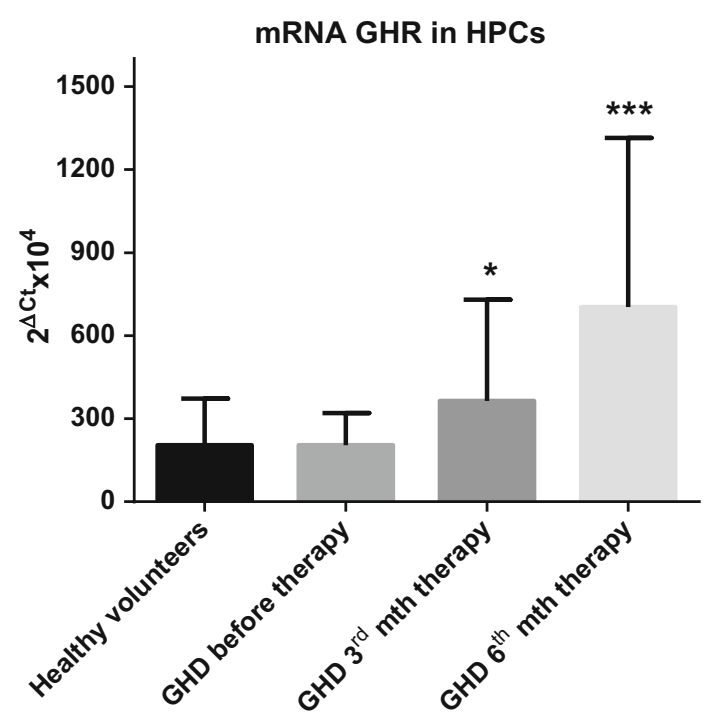

Fig. 1 Expression of GHR mRNA in $\mathrm{CD} 34^{+}$HPCs of controls and GHD patients at different time points. Results are expressed as the mean value $\pm \mathrm{SD}, * P<0.05 ; * * * P<0.001$ vs. GHD patients before therapy

lymphocytes in PB before and during GH-RT (Fig. 2). We observed a significantly higher percentage of circulating $\mathrm{GHR}^{+}$HPCs in patients after 6 months of GH-RT relative to GHD patients before therapy and controls (Fig. 2a). We also observed a slight, but insignificant, increase in the percentage of $\mathrm{GHR}^{+}$HPCs in GHD patients after first 3 months of GH-RT (Fig. 2a). Similarly, we detected significantly increased percentage of $\mathrm{GHR}^{+}$lymphocytes in GHD patients after 6 months of GH-RT relative to GHD patients before therapy (Fig. 2b); importantly, the latter group exhibited significantly decreased numbers of $\mathrm{GHR}^{+}$ lymphocytes compared to controls (Fig. 2b). The kinetics of the number of $\mathrm{GHR}^{+}$HPCs detected during GH-RT largely mimicked the pattern of $G H R$ mRNA expression detected in HPCs.

\section{Increased clonogenicity of BFU-E, but not CFU-GM or CFU-B lymph, from CD34 ${ }^{+}$-enriched HPCs during the course of GH-RT}

Subsequently, we examined the clonogenic potential of $\mathrm{CD} 34^{+}$HPCs in vitro. In GHD group, the number of $\mathrm{CD} 34^{+}$-expanded erythroid BFU-E colonies was significantly lower than that observed in controls (72 vs. $100 \%$, respectively; $P<0.05$; Fig. 3). Furthermore, we noted significantly increased clonogenicity of BFU-E colonies grown from the HPCs collected after 6 months of GH-RT, compared to those collected before GH-RT (108 vs. $72 \%$, respectively; $P<0.05$; Fig. 3). These findings suggest that $\mathrm{GH}$ is involved in the systemic modulation of erythropoiesis in GHD patients. We also assessed the clonogenicity of CFU-GM and CFU-B lymph from HPCs 
A

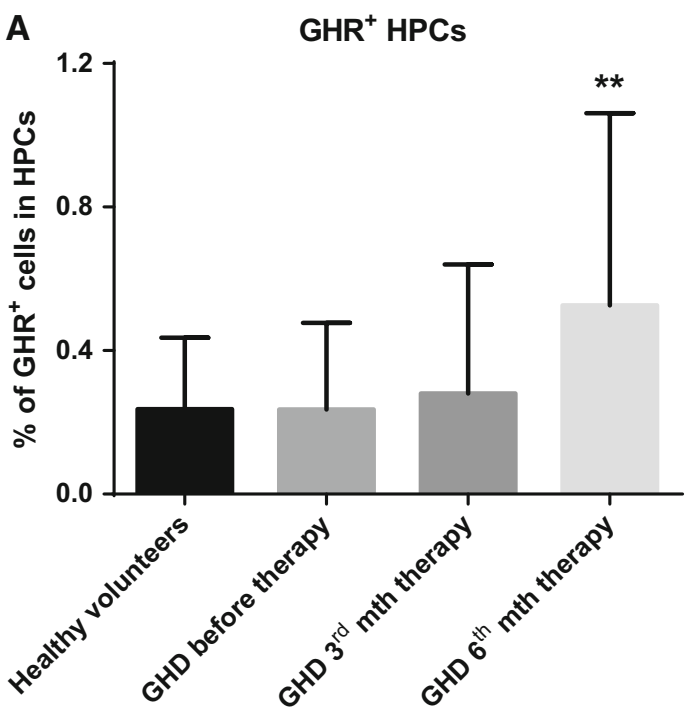

\section{B}

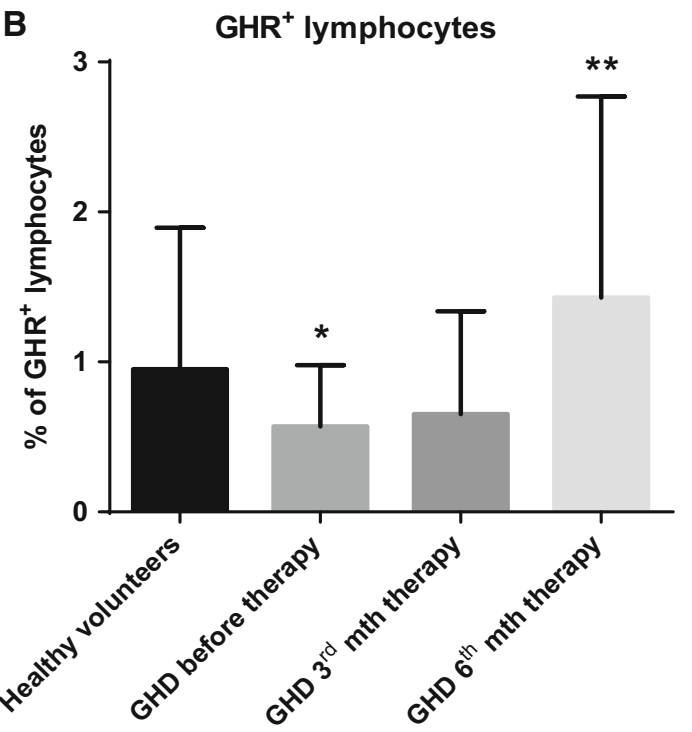

Fig. 2 The percentage of $\mathrm{GHR}^{+} \mathrm{HPCs}$ (a) and $\mathrm{GHR}^{+}$lymphocytes (b) of controls and GHD patients at different time points. The results are expressed as the mean value $\pm \mathrm{SD} . * P<0.05 ; * * P<0.01$ vs. GHD patients before therapy

collected from all groups, but observed no significant changes (Fig. 3b, c).

\section{GH-RT induces cell cycle progression in $\mathrm{CD34}^{+}$- enriched HPCs from GHD patients}

We also investigated whether GH may play a role in modulation of the cell cycle in HPCs following GH-RT. The cell cycle activity in HPCs was measured by the detection of cell cycle phases, i.e., the G1, S, and G2/M. We observed a significantly higher percentage of HPCs in the G1 phase from
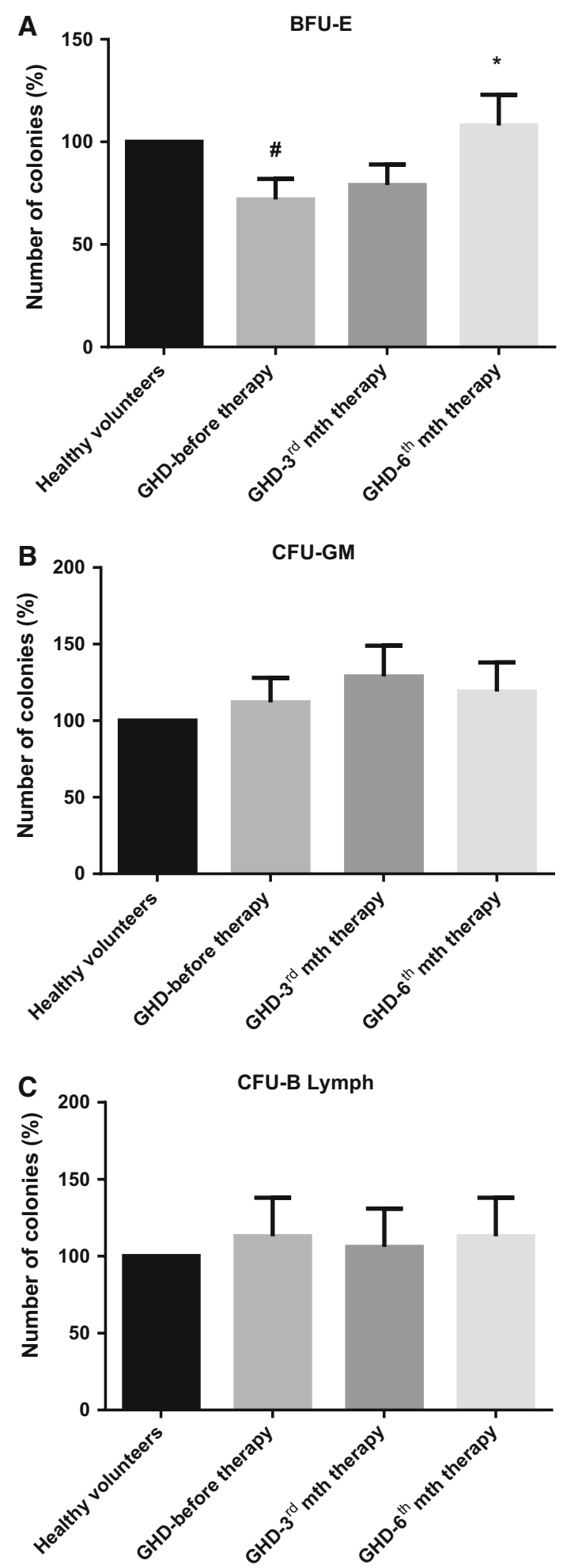

Fig. 3 Comparative analysis of BFU-E (a), CFU-GM (b), and CFUB lymph (c) clonogenicity of CD $34^{+}$HPCs from controls and GHD patients at different time points. The results are expressed as the percentage of the control value, which was set at $100 \%$. The results are presented as the mean value $\pm \mathrm{SD}$. $* P<0.05$ vs. GHD patients before therapy; ${ }^{\#} P<0.05$ vs. control group 


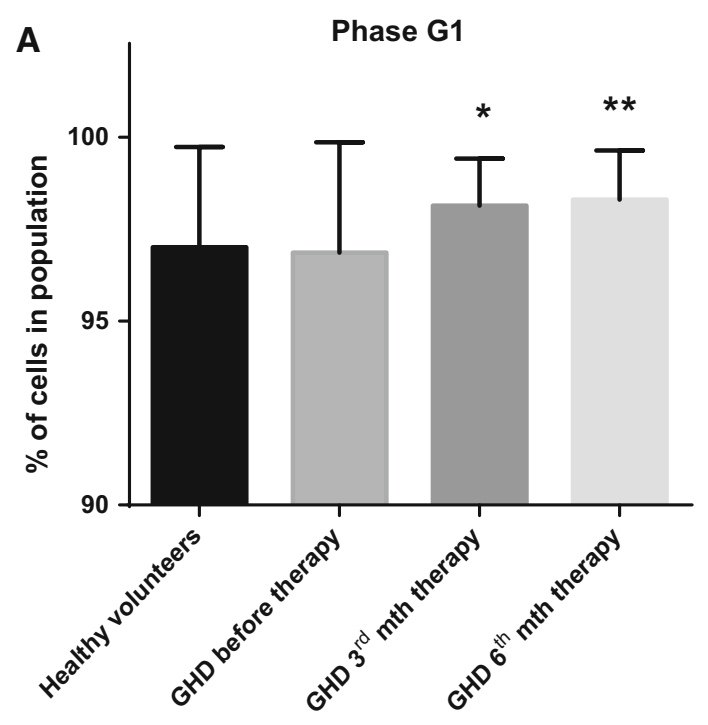

B $2.0 \quad$ Phase $\mathrm{S}$
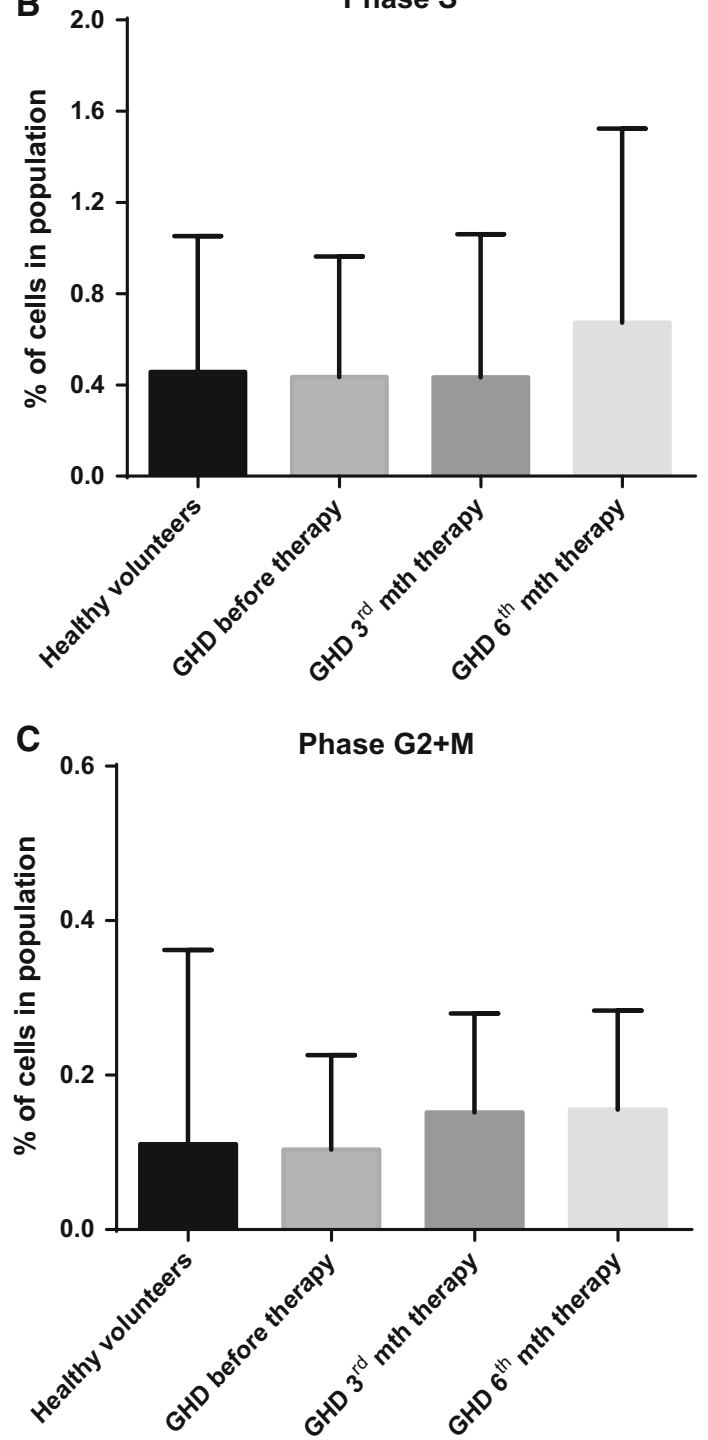

4Fig. 4 Analysis of the cell cycle phases (G1, S, and G2+M) in CD34 ${ }^{+}$HPCs of controls and GHD patients at different time points. The results are expressed as the mean value $\pm \mathrm{SD}$. $* P<0.05$; ** $P<0.01$ vs. GHD patients before therapy

GHD patients after $3(P<0.05)$ and $6(P<0.01)$ months of GH-RT (Fig. 4a). GH treatment also generated an increase of approximately $50 \%$ of the population of HPCs in the G2/ $\mathrm{M}$ phase (3rd and 6th months of GH-RT) and S phase (6th month of GH-RT) compared to untreated patients (Fig. 4b, c). These data demonstrate the potential positive modulation by GH-RT of G1 phase in CD34 ${ }^{+}$cell cycle.

\section{GH-RT up-regulates proliferation-related gene expression in $\mathrm{CD}^{+}{ }^{+}$HPCs in GHD patients}

GH promotes cell proliferation and differentiation. Therefore, we investigated whether GH-RT plays a role in HPC proliferation based on the analysis of the mRNA expression of genes crucial for the induction $(M A P 2 K 1)$ and maintenance (PCNA, CCND1, CCNE1) of cell proliferation. The mRNA levels for all of the examined genes were significantly higher in GHD patients after 3 and 6 months of GH-RT compared to GHD patients before therapy and controls. As shown in Fig. 5, there was around $300 \%$ increase in the mRNA expression of $M A P 2 K 1$ and a similar increase in the mRNA expression of CCND1. Furthermore, we observed a nearly $100 \%$ increase in CCNE1 expression and a nearly $30 \%$ increase in PCNA expression. These findings suggest that GH might be partially involved in the mechanisms responsible for induction of proliferation in HPCs from GHD patients treated with GH-RT.

\section{GH-RT modulates the IGF1 gene and protein expression in GHD patients}

Finally, we decided to verify potential association between GH therapy and expression of IGF1 in vivo. The mean systemic concentrations of IGF1 in GHD patients and control individuals are depicted in Fig. 6a. We found that the levels of IGF1 were significantly higher in GH-treated patients than those before therapy. Interestingly, systemic mean levels of IGF1 significantly differed between untreated GHD patients and their controls. Our data reveal that therapeutic intervention with rhGH provided to GHD patients could augment the global IGF1 production. In order to more extensively examine the expression of IGF1 in PB-derived CD $34^{+} \mathrm{HPCs}$ and to determine whether GH-RT could affect the $I G F 1$ gene transcription, we analyzed the levels of $I G F 1$ gene expression in HPCs collected from all examined groups. As shown in Fig. 6b, the mRNA expression of $I G F 1$ was significantly elevated in GHD patients during GH-RT compared to 

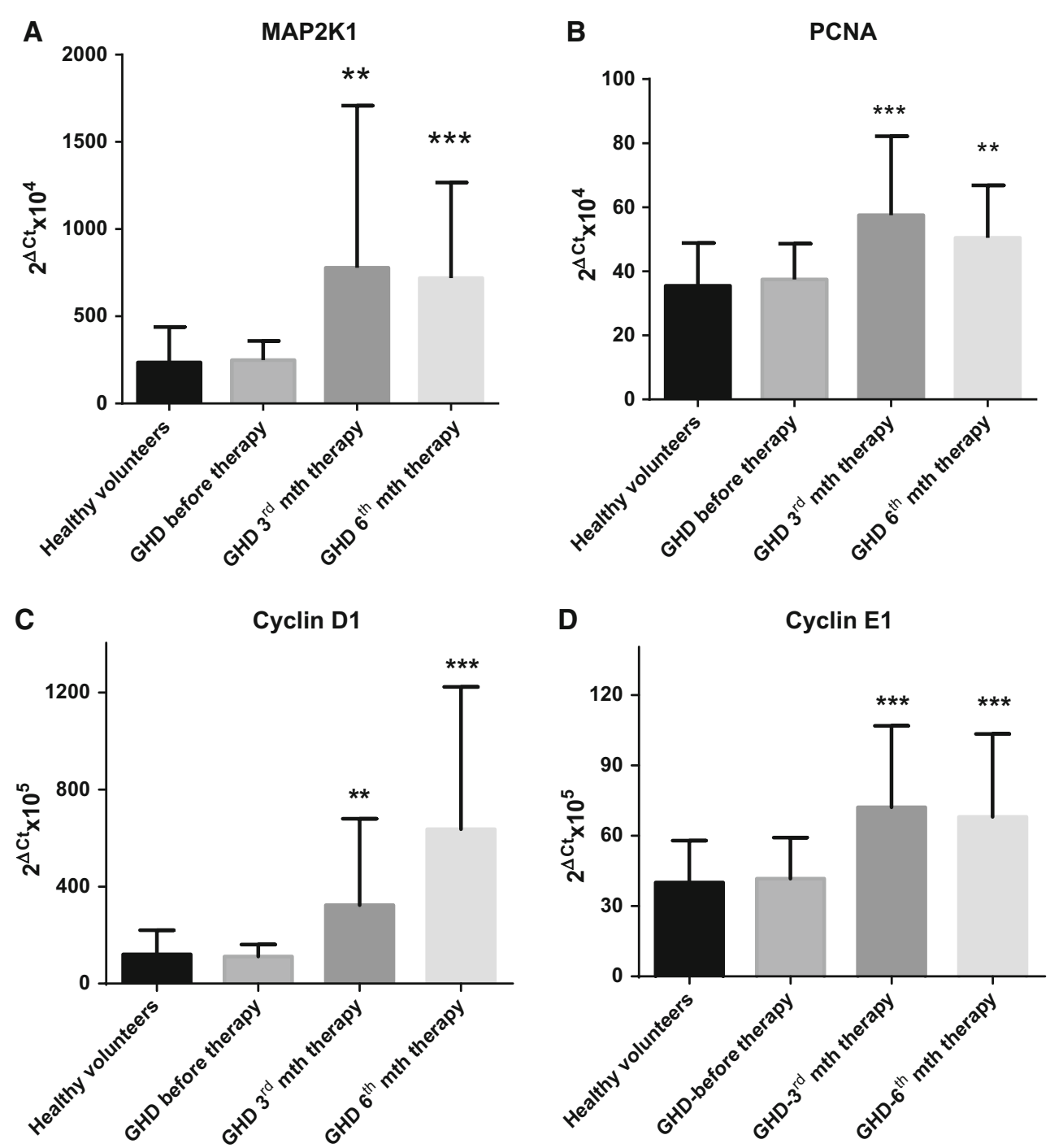

Fig. 5 Expression of cell cycle-regulating genes in PB-derived CD $34^{+}$HPCs of controls and GHD patients at different time points. mRNA expression of the MAP2K1 (a), PCNA (b), CCND1 (c), and

CCNE1 (d) genes was determined. mRNA levels are expressed in arbitrary units as the mean value $\pm \mathrm{SD}$. ${ }^{* *} P<0.01 ; * * * P<0.001$ vs. GHD patients before therapy

untreated patients and controls. No statistically significant differences in terms of $I G F 1$ mRNA levels were found in comparison of the untreated GHD patients and controls. These findings demonstrate that exogenous rhGH could trigger IGF1 gene expression in CD $34^{+}$HPCs from GHD patients, which might have autocrine/paracrine impact on proliferation and survival of these cells.

\section{Whole-genome microarray analysis reveals large- scale alterations in gene expression in $\mathrm{CD34}^{+}$. enriched HPCs in GHD patients during the course of GH-RT}

We analyzed the global gene expression pattern in $\mathrm{CD} 34^{+}$enriched HPCs collected from GHD patients before GH

therapy and at selected time points ( 3 and 6 months postGH-RT) and from controls.. In the GHD patients treated for 6 months with $\mathrm{GH}$, we observed 177 genes that were up-regulated at least twofold $(P<0.05)$ (Table S3). The most significantly up-regulated gene in this group was the early activation antigen CD69 (CD69; 18-fold). CD69 is involved in WBC proliferation and is a signal-transmitting receptor in different subsets of WBCs. The other strongly up-regulated genes in this group included the regulator of G-protein signaling-1 (RGS1; 16-fold), which is involved in B-cell proliferation; asparaginyl-tRNA synthetase (NARS; tenfold), which belongs to the class II family of tRNA synthetases; radical S-adenosyl methionine domain containing 2 (RSAD2; ninefold), encoding viperin, which plays a role in $\mathrm{CD} 4^{+} \mathrm{T}$ cell activation and differentiation; 

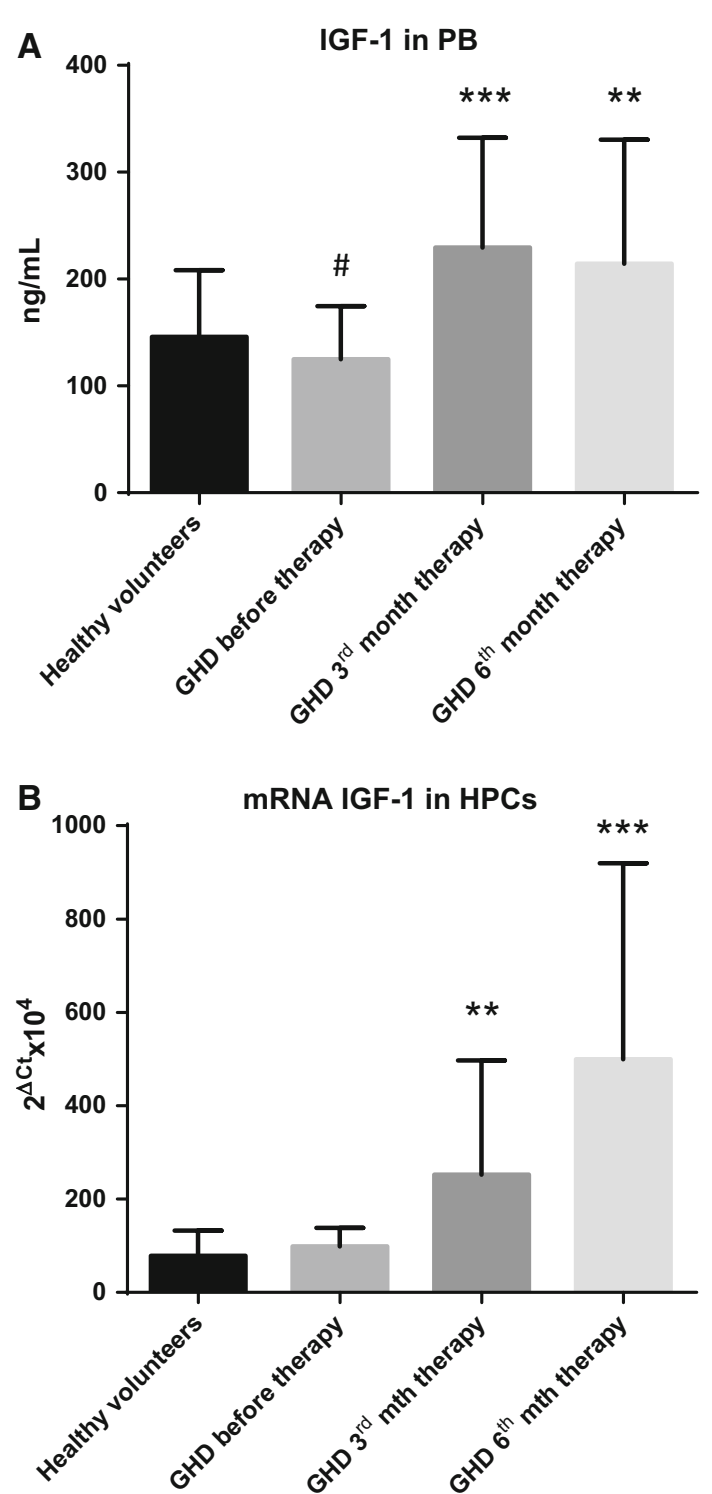

Fig. 6 The levels of IGF1 in peripheral blood (a) and the expression of IGF1 mRNA in CD34 ${ }^{+}$HPCs (b) of controls and GHD patients at different time points. The results are expressed as the mean value $\pm \mathrm{SD}$. $* * P<0.01 ; * * * P<0.001$ vs. GHD patients before therapy; ${ }^{\#} P<0.05$ vs. control group

and pleckstrin (PLEK; sevenfold), which is the platelet and leukocyte major protein $\mathrm{C}$ kinase substrate important for HPC differentiation. Of interest, our analysis identified several interleukins (IL) and related molecules (IL1A, $I L 1 B, I L 8, I L F 2, I L I R N, I L 1 R 1, N F I L 3$, and IL5RA), as well as chemokines (CXCL1, CXCL2, CXCL16, and CCL4) and chemokine receptors $(C X C R 4, C X C R 5, C C R 4$, and $C C R L 2)$, as up-regulated after 6 months of GH-RT. Oncostatin M (OSM; fourfold), a growth regulator, was also found to be over-expressed. Furthermore, we found that several members of the zinc finger protein family, which act as transcriptional regulators involved in mitosis and cell development, including EGR3, ZRANB2, ZNF146, RNF138, ZNF791, and ZNF766, were significantly upregulated after GH-RT. In contrast, in this group 21 genes were significantly down-regulated (Table S4). Similarly, we found that 3 months of GH treatment was responsible for significant up-regulation of 64 genes (Table S5) and down-regulation of 22 genes (Table S6). In addition, we found that prolongation of GH therapy from 3 to 6 months was responsible for significant up-regulation of 71 genes (Table S7) and down-regulation of 146 genes (Table S8).

We also analyzed the differences in gene expression profiles of untreated GHD patients compared to their healthy controls and observed the significant up-regulation of 16 genes (Table S9) and down-regulation of 129 genes (Table S10). Interestingly, untreated GHD patients exhibited significantly down-regulated expression of genes for several ILs and IL-related proteins (ILIB, IL2RB, ILIR2, $I L 7 R, I L F 2$, and $I T K)$ or chemokines and their receptors (CXCL1, CCL4, CXCL16, CCR1, CXCR2, and CXCR1). We also observed down-regulated genes involved in cell cycle control (MAPK14, MDM2, and $H C K$ ), which in general exhibit cytoprotective functions and are essential for cell survival.

Subsequently, 90 genes were specifically up-regulated at least twofold after 6-month GH-RT in GHD patients compared to their controls (Table S11). The genes mostly up-regulated during the course of GH-RT included interferon-induced protein 44-like (IFI44L; ninefold) and interferon-induced protein with tetratricopeptide repeats-1 (IFIT1; sevenfold), which are both members of the interferon-related immune response signaling pathway. Of importance, our analysis identified significant increases in the expression of essential regulators of cell cycle progression, such as CDK6, SPIN1, TBLIXR1,JUN and APEX1. Moreover, among the highly up-regulated genes, we observed those related to the positive regulation of hematopoiesis, including MYB, HPGDS, LY6E, and two markers of hematopoietic stem cells, CD133 (PROM1) and CD34. Furthermore, we found that, in the same period, the $\mathrm{GH}$ therapy induced the significant down-regulation of 45 genes (Table S12). In contrast, the 3-month-treatment with $\mathrm{GH}$ was responsible for significant up-regulation of 21 genes (Table S13) and down-regulation of 26 genes (Table S14).

Next, all of the differentially expressed genes were classified according to the GO classification of biological processes. Functional analysis using GO revealed that a number of pathways were specifically and diversely represented in the $\mathrm{CD} 34^{+}$-enriched HPCs from GHD patients and controls. We observed that genes involved in the regulation of cell proliferation, regulation of cytokine production, signal transduction, regulation of angiogenesis and endothelial cell proliferation, positive regulation of immune system 
processes, regulation of gene expression, regulation of cell death, regulation of cellular metabolic process, regulation of homeostatic process, positive regulation of cellular processes, positive regulation of cytokine production, regulation of hormone transport and secretion, positive regulation of defense responses, regulation of responses to stress, wounding, and hypoxia were among the most up-regulated during GH-RT. A summary of the distribution of the selected gene clusters according to the GO classification results is presented in Fig. 7.

\section{Discussion}

While the role of $\mathrm{GH}$ in hematopoiesis has been studied in several in vitro studies and animal models, the contribution of $\mathrm{GH}$ to hematopoiesis in GHD patients undergoing $\mathrm{rhGH}$ therapy remains incompletely understood. Although a number of GH-regulated genes have been identified, genes relating $\mathrm{GH}$ to the biology of HSPCs remain largely unknown. Accordingly, we sought to investigate the effects of 6-month GH-RT on cell cycle and HPCs proliferation in
Fig. 7 Global gene expression changes in $\mathrm{CD}_{3} 4^{+}$HPCs of controls and GHD patients at different time points (before GH-RT and in the 3rd and 6th months of GH-RT). The heatmap represents the expression levels of highly over-expressed genes (fold change $>2$ ). Individual genes are designated according to the GO classification of specific biological processes listed on the left side of the graph. Each column comprises a set of horizontal lines, each representing a single gene. The levels of gene expression are indicated on a color scale, with yellow corresponding to the highest level of expression and blue corresponding to the lowest level. The expression range of the analyzed genes is shown below the graph. The upper diagram (a) depicts large-scale alterations in gene expression between HPCs collected in the 3rd and 6th months of GH-RT compared to those collected before GH-RT. The lower diagram (b) presents large-scale alterations in gene expression between HPCs collected during the course of GH-RT compared to those collected before $\mathrm{GH}$ RT as well as HPCs obtained from controls
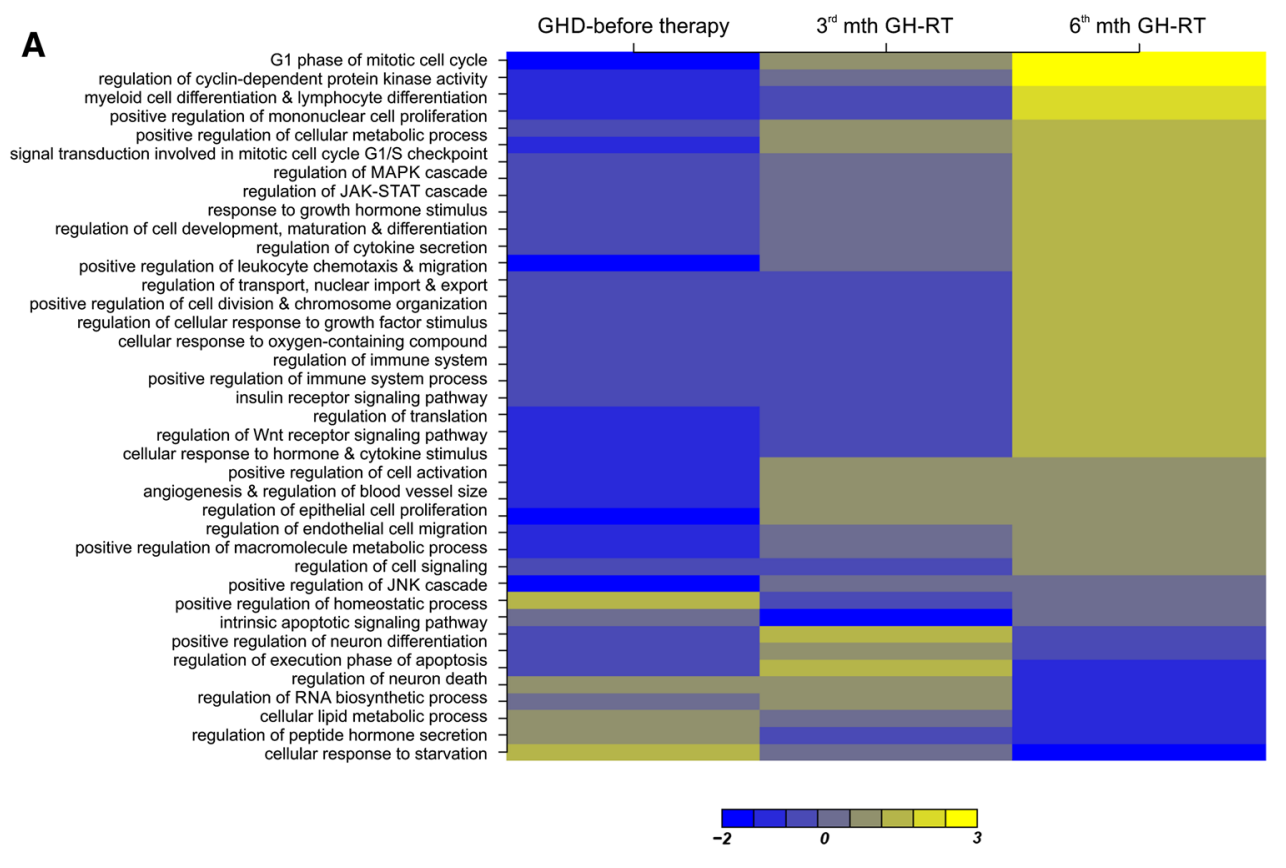

B

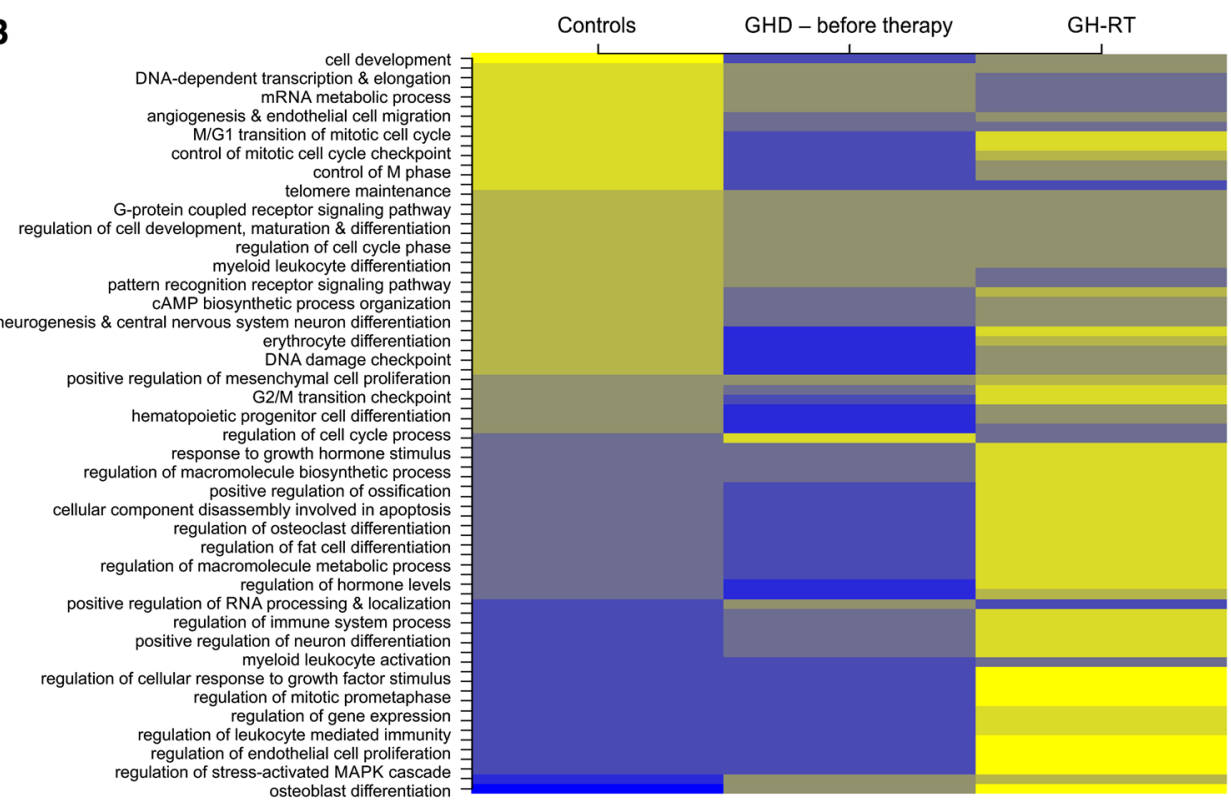


children with GHD. To our knowledge, the present study is the first to evaluate $\mathrm{CD} 34^{+}$-enriched HPC functions with respect to GHD in children.

A considerable amount of evidence suggests that $\mathrm{GH}$ plays an important role in the modulation of hematopoiesis and exerts biological effects on erythropoiesis [7], granulopoiesis [8], and lymphopoiesis [21]. Importantly, the study of Sharma et al. on transgenic mice revealed that a genetic 100-fold reduction in $\mathrm{GH}$ expression did not affect hematopoietic cell expansion, maturation, or differentiation [22]. However, it is challenging to apply results obtained in vitro and in animal models to human physiology. As GHR expression is a key target that influences the effectiveness of $\mathrm{GH}$, the analysis of its expression in HPCs is invaluable. The expression of GHR at the mRNA and protein levels was previously detected in human mature $\mathrm{T}$ and B lymphocytes and monocytes/macrophages [23, 24]. However, there is a lack of studies providing the evidence that GHR is expressed in CD34+-enriched HPCs from PB of GHD children. We observed in our study that GH-RT significantly augmented the basal expression levels of mRNA for GHR. Similarly, Hattori et al. showed previously a significant positive correlation between $\mathrm{GH}$ concentration and mRNA expression for GHR in normal human B lymphocytes cultured in vitro [23]. Lin et al. reported that, in mice bearing subcutaneous tumors naturally expressing GHR protein, the GHR mRNA expression was significantly increased after $\mathrm{GH}$ treatment [25]. These results indicate that the expression of $G H R$ mRNA could be stimulated by increased GH concentrations. Indeed, we observed increased GHR mRNA expression and percentage of $\mathrm{GHR}^{+}$HPCs in patients treated with GH-RT for 6 months. Similarly, the population of $\mathrm{GHR}^{+}$lymphocytes was increased significantly $(P<0.01)$ after GH-RT. Furthermore, we observed that the quantity of $\mathrm{GHR}^{+}$lymphocytes in untreated GHD patients was significantly decreased compared to that of controls. GH exerts effects on cell survival and proliferation also through its direct effects on several types of cells, including chondrocyte progenitors [26]. To further explore the potential direct GH influence on HPC proliferation and differentiation, we assessed the effect of GH-RT on HPCs clonogenicity. We demonstrated that clonogenic potential of $\mathrm{CD} 34^{+}$-expanded BFU-E was significantly higher in GHD patients treated with GH-RT for 6 months than that before therapy. It is possible that this effect might be a result of the modulatory action of $\mathrm{GH}$ on the production of erythropoietin (EPO), as increased concentrations of $\mathrm{GH}$ augment the levels of EPO in GHD patients with developed anemia [27, 28], possibly due to increased hepatic synthesis of EPO [29]. However, in in vitro cultures containing an established amount of EPO, we observed increased growth only in the samples collected from patients treated previously with GH-RT. Indeed, previous studies have demonstrated that GH directly enhances the in vitro proliferation of erythroid precursors [7], and GH therapy had a stimulatory effect on the growth of BFU-E progenitors collected from 11 children with IGHD [30]. The observed significant increase in the reactivity of erythroid progenitors from GHD children during GH-RT may be the result of increased bioavailability of free, unbound GHR molecules on the progenitor cell surface. Additionally, GH may act as a potent direct cell growth stimulator, as shown in vitro using murine Friend erythroleukemia cells and human erythroleukemia cell line K562 [31, 32]. Taken together, these data suggest that the GH/GHR biological axis can directly induce signal transduction pathways involved in HSPC proliferation distinct from EPO-dependent pathways. This hypothesis is consistent with our another finding that $\mathrm{CD} 34^{+}$cells of GHD patients before therapy exhibited considerable growth reduction of BFU-E compared to those of the control subjects.

The GH-activated GHR induces pro-survival mechanisms downstream of the classical JAK-STAT pathway and finally initiates target gene transcription, which may result in increased stem cell cycling [33]. This potential mechanism of direct GH action in HPCs strongly correlates with our observations from the 3rd and 6th months of $\mathrm{GH}$ RT, showing significantly increased numbers of $\mathrm{CD} 34^{+}$ cells in G1 phase of the cell cycle, together with considerable increase of HPCs numbers in the $\mathrm{S}$ and $\mathrm{G} 2+\mathrm{M}$ phases, indicating that the number of proliferating cells might be increased during GH therapy. Likewise, GH simultaneously increased the mRNA expression of genes involved in cell cycle regulation, such as $M A P 2 K 1$, cyclins $D 1$ and $E 1$, and PCNA, in CD34 ${ }^{+}$HPCs from GH-treated individuals. These data correlate strongly with the changes in erythrocyte-related parameters including RBC, HCT, $\mathrm{HGB}, \mathrm{MCV}$, and MCH measured in the PB. Importantly, adult patients with $\mathrm{GH}$ deficiency have been characterized in several studies as anemic patients $[30,34]$. In our study, at baseline the $\mathrm{RBC}$ numbers were decreased with reduced $\mathrm{MCV}$ and $\mathrm{MCH}$ values. In contrast, these values increased significantly within 6 months of GH-RT. Similarly, in the clinical study of GHD adults performed by Christ et al., the administration of $\mathrm{GH}$ led to an increase in RBC mass, indicating that $\mathrm{GH}$ may have a direct in vivo regulatory effect on erythropoiesis [35]. Additionally, Strauch et al. reported that, in acromegalic patients, RBC mass was increased but returned to normal values after curative surgery [36]. On the other hand, GHD patients suffer from significantly decreased HGB concentrations, regardless of their age. Subsequently, the HGB levels were significantly increased during GH-RT. Importantly, the final HGB concentration measured in $\mathrm{GH}$-treated patients was maintained within the normal ranges and did not exhibit any 
superphysiological concentrations, as it has been reported after treatment with recombinant EPO [34]. Similarly, Miniero et al. evaluated 279 children with IGHD and diagnosed moderate anemia in 48 patients [14]. Moreover, the HGB levels significantly increased during GH-RT, and all examined children exhibited normal HGB values after 48 months of GH therapy [14]. GH is believed to increase the necessity for oxygen transport to the peripheral tissues due to its general anabolic effects, potentially resulting in increased HGB levels in PB. Together, these data support the concept that the GH/GHR axis directly promotes erythropoiesis in vivo in GHD children.

Although the liver is the major site of IGF-1 production (70 \%) after stimulation by GH, IGF-1 is also produced locally by peripheral cells under basal conditions and in response to different stimuli [37]. Thus, local production of IGF1 also plays a role in the growth and differentiation of tissues, and several studies established the critical importance of IGF action for the development and normal function of hematopoietic system. It was demonstrated that IGF1 stimulates the growth, proliferation, and survival of different hematopoietic cell populations in vitro and inhibits their apoptosis [reviewed in detail in 38]. Moreover, Tsarfaty et al. observed that human IGF1 promotes hematopoietic growth in vivo in mice [15]. Likewise, GH and IGF1 administration enhanced reconstitution of the immune system and hematopoiesis after marrow transplantation in mice [39, 40]. Alpdogan et al. demonstrated that lymphoid and myeloid reconstitution after marrow transplantation was enhanced by IGF1 administration through the expansion of thymic precursor cell populations [41]. Vidal et al. reported that IGF1 was in the group of 52 acutely GH-activated genes in the liver $2 \mathrm{~h}$ after GH treatment [42]. Further analyses in mice with a targeted deletion of GHR have confirmed its key roles in controlling of IGF1 production [43]. In this notion, we conducted a preliminary analysis of the potential influence of GH-RT on IGF1 mRNA expression in CD34 + HPCs from GHD patients and found that GH therapy significantly elevated its levels compared to GHD patients before therapy and controls. We also found the significantly higher IGF1 concentration in PB of GHD patients in course of GH-RT, which is in agreement with previous studies [44, 45]. From the molecular stand point, increased levels of IGF1 might be caused by several molecular mechanisms, which are GH dependent [46] and GH independent [47], with the liver as the main source of circulating hormone. However, our study demonstrates that CD34+HPCs can be a GH-dependent source of IGF1, which next may play pro-survival role and could potentially stimulate HPC proliferation in autocrine/paracrine manner. Moreover, we have found that exogenous GH is biologically active in $\mathrm{CD} 34^{+}$HPCs and stimulates the appropriate signal transduction pathways through GH/GHR signaling in these cells.
Finally, we have demonstrated for the first time that GH treatment is associated with specific changes in the global pattern of gene expression, which triggers diverse signaling pathways within HPCs from GHD children. A total of 177 genes were found to be differentially expressed after 6-month GH therapy compared to subjects before treatment. These genes were mainly associated with biological processes such as the regulation of cell cycle progression and mitosis, cell proliferation, hematopoietic and immune cell proliferation, maturation and differentiation, general cell development and differentiation, the regulation of translation, mRNA processing, cell migration and adhesion, cytokine secretion, intracellular and extracellular signaling pathways, cell metabolism, cell chemotaxis, angiogenesis, and apoptosis inhibition (Fig. 7a). Interestingly, our microarray experiments revealed that the three most strongly up-regulated genes were involved in hematopoietic T- and B-cell proliferation, activation, and differentiation. The above results could indicate that these GHdependent changes in immune networks may improve immune functions and may therefore reverse some hematopoietic cell dysfunctions observed in GHD patients. Indeed, it has been observed that thymic function can be significantly enhanced by GH therapy [48]. Additionally, GH therapy was found to significantly increase the expression of several genes involved in signaling pathways of hematopoietic and immune cells, including cytokines (IL1A, IL1B, IL8, and ILF2) and chemokines (CCLA, CXCL1, CXCL2, and CXCL16), which are associated with cell proliferation and chemotaxis. Moreover, GH therapy induced the gene expression of tRNA synthetase, a crucial enzyme implicated in the synthesis of cellular components, i.e., nucleic acids, contributing in cell cycle control, mRNA transcription, splicing, and nuclear export of tRNAs [49]. Together, the above results imply that exogenous rhGH is likely to induce significant changes in cell cycle regulation, intracellular signaling, and cytokine production in HPCs from GHD children.

We further analyzed the influence of GH deficiency on gene expression changes in CD $34^{+}$HPCs. Specifically, the genes that were down-regulated due to GH deficiency could be broadly clustered into the following categories: cell cycle regulation and mitosis, hematopoietic cell lineage development and differentiation, cell chemotaxis, angiogenesis and endothelial cell migration, cytokine production and secretion, cytokine-cytokine receptor interaction, receptor signaling pathways, lipid metabolism, and biosynthesis of cell components (Fig. 7b). The most downregulated gene in HPCs from GHD subjects was prostaglandin-endoperoxide synthase-2 (PTGS2), which acts both as a dioxygenase and a peroxidase, and thus is involved in the inflammation as well as the stimulation of mitosis [50]. Furthermore, the $c-M Y B$ gene encoding the 
proto-oncogene, which controls HSPC proliferation and differentiation [51], was also significantly down-regulated in GHD patients.. The above results demonstrate that GH deficiency can down-regulate the expression of genes that appear to be essential for cell cycle regulation, cell survival and proliferation, and differentiation of HPCs. Importantly, the changes in gene expression pattern found by our group in circulating HPCs from GHD children after 6-month GH therapy were also observed by other groups in mature PBderived mononuclear cells from GHD children treated with $\mathrm{GH}$ for 1 or 3 months [52, 53]. In all analyses, $\mathrm{GH}$ treatment was associated with expression changes of genes involved in the processes such as cell function and metabolism, cell cycle, and cell migration. In particular, Stevens et al. observed that 1-month therapy with $\mathrm{GH}$ induced changes in MAPK- and SOS-mediated signaling pathways (e.g., IGF1) that are strongly related with cell growth and proliferation [52]. Similarly, 3-month GH treatment significantly induced expression of genes encoding regulators of G-protein signaling (RGS1), nuclear receptors (NRF4A2), and members of TNF-alpha family (TNFAIP3), as well as genes implicated in $\mathrm{GH}$ signaling, including SOCS1 [53]. In addition, Fernandez-Perez et al. revealed that, among unique 163 genes differentially expressed in PB-derived mononuclear cells collected before and after 1-month of GH treatment in adult GHD patients, there were markedly expressed genes involved in SOCS-dependent intracellular signaling cascade $(A S B 6)$ or implicated in regulation of cell cycle progression (PSMD8), immune response $(I K)$, signal transduction $(P A B P N 1)$, or mRNA processing (PPP2R5C) [54]. Not surprisingly, the observed gene expression changes strongly involve the IGF1 pathway; therefore, the observed changes in gene expression in different cell populations circulating in PB could reflect both direct and indirect $\mathrm{GH}$ actions.

In conclusion, we report a direct cause and effect association between GHD and hematopoiesis in children. Our study demonstrates that CD34 ${ }^{+}$HPCs are sensitive to the pathophysiological conditions present in GHD and therapeutic $\mathrm{GH}$ replacement lasting at least 6 months. Our data also showed that GHD significantly impacts the proliferative potential of HPCs and their differentiation into erythroid-committed progenitors. Of note, we consider this work as an exploratory pilot study as the number of ageand sex-matched patients was small. Our observations may help improve the understanding of the interactions between rhGH and human hematopoiesis.

Acknowledgment This work was supported by the Polish National Science Center Grant No. N N402 467539 (to BM).

Conflict of interest All authors disclose any actual or potential conflict of interest with the submission.
Open Access This article is distributed under the terms of the Creative Commons Attribution 4.0 International License (http:// creativecommons.org/licenses/by/4.0/), which permits unrestricted use, distribution, and reproduction in any medium, provided you give appropriate credit to the original author(s) and the source, provide a link to the Creative Commons license, and indicate if changes were made.

\section{References}

1. A.J. Brooks, M.J. Waters, The growth hormone receptor: mechanism of activation and clinical implications. Nat. Rev. Endocrinol. 6, 515-525 (2010)

2. K.A. Slot, J. Kastelijn, A. Bachelot, P.A. Kelly, N. Binart, K.J. Teerds, Reduced recruitment and survival of primordial and growing follicles in $\mathrm{GH}$ receptor-deficient mice. Reproduction 131, 525-532 (2006)

3. J. Wang, J. Zhou, C.M. Cheng, J.J. Kopchick, C.A. Bondy, Evidence supporting dual, IGF-I-independent and IGF-I-dependent, roles for $\mathrm{GH}$ in promoting longitudinal bone growth. J. Endocrinol. 180, 247-255 (2004)

4. S. McLenachan, M.G. Lum, M.J. Waters, A.M. Turnley, Growth hormone promotes proliferation of adult neurosphere cultures. Growth Horm. IGF Res. 19, 212-218 (2009)

5. M.J. Waters, A.J. Brooks, Growth hormone and cell growth. Endocr. Dev. 23, 86-95 (2012)

6. N. Hattori, Expression, regulation and biological actions of growth hormone $(\mathrm{GH})$ and ghrelin in the immune system. Growth Horm. IGF Res. 19, 187-197 (2009)

7. S. Merchav, I. Tatarsky, Z. Hochberg, Enhancement of erythropoiesis in vitro by human growth hormone is mediated by insulinlike growth factor I. Br. J. Haematol. 70, 267-271 (1988)

8. S. Merchav, I. Tatarsky, Z. Hochberg, Enhancement of human granulopoiesis in vitro by biosynthetic insulin-like growth factor $\mathrm{I} /$ somatomedin $\mathrm{C}$ and human growth hormone. J. Clin. Invest. 81, 791-797 (1988)

9. L.A. Welniak, R. Sun, W.J. Murphy, The role of growth hormone in T-cell development and reconstitution. J. Leukoc. Biol. 71, 381-387 (2002)

10. R.A. French, S.R. Broussard, W.A. Meier, C. Minshall, S. Arkins, J.F. Zachary, R. Dantzer, K.W. Kelley, Age-associated loss of bone marrow hematopoietic cells is reversed by $\mathrm{GH}$ and accompanies thymic reconstitution. Endocrinology 143, 690-699 (2002)

11. B.J. Chen, D. Deoliveira, I. Spasojevic, G.D. Sempowski, C. Jiang, K. Owzar, X. Wang, D. Gesty-Palmer, J.M. Cline, J.D. Bourland, G. Dugan, S.K. Meadows, P. Daher, G. Muramoto, J.P. Chute, N.J. Chao, Growth hormone mitigates against lethal irradiation and enhances hematologic and immune recovery in mice and nonhuman primates. PLoS ONE 5, e11056 (2010)

12. summary statement of the GH Research Society, Growth Hormone Research Society Consensus guidelines for the diagnosis and treatment of growth hormone $(\mathrm{GH})$ deficiency in childhood and adolescence. J. Clin. Endocrinol. Metab. 85, 3990-3993 (2000)

13. M. Scacchi, L. Danesi, A. Cattaneo, E. Valassi, F.P. Giraldi, C. Argento, E. D'Angelo, N. Mirra, V. Carnelli, L. Zanaboni, M.D. Cappellini, F. Cavagnini, Growth hormone deficiency (GHD) in adult thalassaemic patients. Clin. Endocrinol. 67, 790-795 (2007)

14. R. Miniero, F. Altomare, M. Rubino, P. Matarazzo, C. Montanari, A. Petri, G. Raiola, G. Bona, Effect of recombinant human growth hormone (rhGH) on hemoglobin concentration in children 
with idiopathic growth hormone deficiency-related anemia. J. Pediatr. Hematol. Oncol. 34, 407-411 (2012)

15. G. Tsarfaty, D.L. Longo, W.J. Murphy, Human insulin-like growth factor I exerts hematopoietic growth-promoting effects after in vivo administration. Exp. Hematol. 22, 1273-1277 (1994)

16. J.P. Monson, Long-term experience with GH replacement therapy: efficacy and safety. Eur. J. Endocrinol. 148(Suppl 2), S9S14 (2003)

17. G. Valerio, S. Di Maio, M. Salerno, A. Argenziano, R. Badolato, A. Tenore, Assessment of red blood cell indices in growth-hormone-treated children. Horm. Res. 47, 62-66 (1997)

18. E.A. Eugster, M. Fisch, E.C. Walvoord, L.A. DiMeglio, O.H. Pescovitz, Low hemoglobin levels in children with in idiopathic growth hormone deficiency. Endocrine. 18, 135-136 (2002)

19. S. Bergamaschi, C. Giavoli, E. Ferrante, A. Lania, R. Rusconi, A. Spada, P. Beck-Peccoz, Growth hormone replacement therapy in growth hormone deficient children and adults: effects on hemochrome. J. Endocrinol. Invest. 29, 399-404 (2006)

20. C. Meazza, I. Bonomelli, S. Pagani, P. Travaglino, K. Laarej, F. Cantoni, M. Bozzola, Effect of human recombinant growth hormone therapy on circulating levels of EPO and G-CSF in short children. J. Pediatr. Endocrinol. Metab. 22, 837-843 (2009)

21. M.E. Geffner, N. Bersch, B.M. Lippe, R.G. Rosenfeld, R.L. Hintz, D.W. Golde, Growth hormone mediates the growth of T-lymphoblast cell lines via locally generated insulin-like growth factor-I. J. Clin. Endocrinol. Metab. 71, 464-469 (1990)

22. Y. Sharma, K. Flurkey, C.M. Astle, D.E. Harrison, Mice severely deficient in growth hormone have normal hematopoiesis. Exp. Hematol. 33, 776-783 (2005)

23. N. Hattori, T. Saito, T. Yagyu, B.H. Jiang, K. Kitagawa, C. Inagaki, $\mathrm{GH}, \mathrm{GH}$ receptor, $\mathrm{GH}$ secretagogue receptor, and ghrelin expression in human T cells, B cells, and neutrophils. J. Clin. Endocrinol. Metab. 86, 4284-4291 (2001)

24. E. Bozzola, S. Pagani, C. Meazza, E. Cortis, D. Lisini, K. Laarej, M. Bozzola, Changes in growth hormone receptor gene expression during therapy in children with juvenile idiopathic arthritis. Horm. Res. Paediatr. 77, 52-58 (2012)

25. Y. Lin, S. Li, P. Cao, L. Cheng, M. Quan, S. Jiang, The effects of recombinant human $\mathrm{GH}$ on promoting tumor growth depend on the expression of $\mathrm{GH}$ receptor in vivo. J. Endocrinol. 211, 249-256 (2011)

26. A.L. Rosenbloom, Physiology of Growth. Ann. Nestlé 65, 97-108 (2007)

27. S.M. Ten Have, A.J. van der Lely, S.W. Lamberts, Increase in haemoglobin concentrations in growth hormone deficient adults during human recombinant growth hormone replacement therapy. Clin. Endocrinol. 47, 565-570 (1997)

28. M. Sohmiya, Y. Kato, Effect of long-term administration of recombinant human growth hormone (rhGH) on plasma erythropoietin (EPO) and haemoglobin levels in anaemic patients with adult GH deficiency. Clin. Endocrinol. 55, 749-754 (2001)

29. M. Sohmiya, Y. Kato, Human growth hormone and insulin-like growth factor-I inhibit erythropoietin secretion from the kidneys of adult rats. J. Endocrinol. 184, 199-207 (2005)

30. Y. Barak, Z. Zadik, Y. Karov, T. Hahn, Enhanced response of human circulating erythroid progenitor cells to hGH and to IGF-I in children with insufficient growth hormone secretion. Pediatr. Res. 32, 282-285 (1992)

31. D.W. Golde, N. Bersch, C.H. Li, Growth hormone modulation of murine erythroleukemia cell growth in vitro. Proc. Natl. Acad. Sci 75, 3437-3439 (1978)

32. C. Gauwerky, D.W. Golde, C.H. Li, Growth hormone polypeptides stimulate proliferation of K562 human erythroleukemia cells. J. Clin. Endocrinol. Metab. 51, 1208-1210 (1980)
33. B.L. Conway-Campbell, A.J. Brooks, P.J. Robinson, M. Perani, M.J. Waters, The extracellular domain of the growth hormone receptor interacts with coactivator activator to promote cell proliferation. Mol. Endocrinol. 22, 2190-2202 (2008)

34. M. Sohmiya, K. Ishikawa, Y. Kato, Stimulation of erythropoietin secretion by continuous subcutaneous infusion of recombinant human $\mathrm{GH}$ in anemic patients with chronic renal failure. Eur. J. Endocrinol. 138, 302-306 (1998)

35. E.R. Christ, M.H. Cummings, N.B. Westwood, B.M. Sawyer, T.C. Pearson, P. Sönksen, D.L. Russell-Jones, The importance of growth hormone in the regulation of erythropoiesis, red cell mass, and plasma volume in adults with growth hormone deficiency. J. Clin. Endocrinol. Metab. 82, 2985-2990 (1997)

36. G. Strauch, A. Lego, F. Therain, H. Bricaire, Reversible plasma and red blood cells volumes increases in acromegaly. Acta. Endocrinol. 85, 465-478 (1977)

37. C.J. Rosen, M. Pollak, Circulating IGF-I: new perspectives for a new century. Trends Endocrinol. Metab. 10, 136-141 (1999)

38. T.J. Smith, Insulin-like growth factor-I regulation of immune function: a potential therapeutic target in autoimmune diseases? Pharmacol. Rev. 62, 199-236 (2010)

39. V. de Mello-Coelho, D.M. Villa-Verde, M. Dardenne, W. Savino, Pituitary hormones modulate cell-cell interactions between thymocytes and thymic epithelial cells. J. Neuroimmunol. 76, 39-49 (1997)

40. Z.G. Tian, M.A. Woody, R. Sun, L.A. Welniak, A. Raziuddin, S. Funakoshi, G. Tsarfaty, D.L. Longo, W.J. Murphy, Recombinant human growth hormone promotes hematopoietic reconstitution after syngeneic bone marrow transplantation in mice. Stem Cells 16, 193-199 (1998)

41. O. Alpdogan, S.J. Muriglan, B.J. Kappel, E. Doubrovina, C. Schmaltz, R. Schiro, J.M. Eng, A.S. Greenberg, L.M. Willis, J.A. Rotolo, R.J. O'Reilly, M.R. van den Brink, IGF-1 enhances lymphoid and myeloid reconstitution after allogeneic bone marrow transplantation. Transplantation 75, 1977-1983 (2003)

42. O.M. Vidal, R. Merino, E. Rico-Bautista, L. Fernandez-Perez, D.J. Chia, J. Woelfle, M. Ono, B. Lenhard, G. Norstedt, P. Rotwein, A. Flores-Morales, In vivo transcript profiling and phylogenetic analysis identifies suppressor of cytokine signaling 2 as a direct signal transducer and activator of transcription $5 \mathrm{~b}$ target in liver. Mol. Endocrinol. 21, 293-311 (2007)

43. Y. Zhou, B.C. Xu, H.G. Maheshwari, L. He, M. Reed, M. Lozykowski, S. Okada, L. Cataldo, K. Coschigamo, T.E. Wagner, Baumann G \& Kopchick JJ A mammalian model for Laron syndrome produced by targeted disruption of the mouse growth hormone receptor/binding protein gene (the Laron mouse). Proc. Natl. Acad. Sci. 94, 13215-13220 (1997)

44. K. Chihara, Y. Kato, H. Kohno, K. Takano, T. Tanaka, A. Teramoto, A. Shimatsu, Safety and efficacy of growth hormone during extended treatment of adult Japanese patients with GH deficiency. Growth Horm. IGF Res. 18, 307-317 (2008)

45. J. Moock, C. Albrecht, N. Friedrich, H. Völzke, M. Nauck, M. Koltowska-Haggström, T. Kohlmann, H. Wallaschofski, Healthrelated quality of life and IGF-1 in GH-deficient adult patients on GH replacement therapy: analysis of the German KIMS data and the Study of Health in Pomerania. Eur. J. Endocrinol. 160, 17-24 (2009)

46. M.J. Waters, A.J. Brooks, Growth Hormone and Cell Growth. In: P.E. Mullis (ed.): Developmental Biology of GH Secretion, Growth and Treatment. Endocr Dev. vol 23, pp. 86-95. Karger, Basel (2012)

47. S. Zanconato, D.Y. Moromisato, M.Y. Moromisato, J. Woods, J.A. Brasel, D. Leroith, C.T. Roberts, D.M. Cooper, Effect of training and growth hormone suppression on IGF1 mRNA in young rats. J. Appl. Physiol. 76, 2204-2209 (1994) 
48. D.A. Weigent, Lymphocyte GH-axis hormones in immunity. Cell Immunol. 285, 118-132 (2013)

49. C. Francklyn, J.J. Perona, J. Puetz, Y.M. Hou, Aminoacyl-tRNA synthetases: versatile players in the changing theater of translation. RNA 8, 1363-1372 (2002)

50. S.L. Brown, T.E. Riehl, M.R. Walker, M.J. Geske, J.M. Doherty, W.F. Stenson, T.S. Stappenbeck, Myd88-dependent positioning of Ptgs2-expressing stromal cells maintains colonic epithelial proliferation during injury. J. Clin. Invest. 117, 258-269 (2007)

51. K.T. Greig, S. Carotta, S.L. Nutt, Critical roles for c-Myb in hematopoietic progenitor cells. Semin. Immunol. 20, 247-256 (2008)

52. A. Stevens, P. Clayton, L. Tatò, H.W. Yoo, M.D. RodriguezArnao, J. Skorodok, G.R. Ambler, M. Zignani, J. Zieschang, G.
Della Corte, B. Destenaves, A. Champigneulle, J. Raelson, P. Chatelain, Pharmacogenomics of IGF1 generation during GH treatment in children with GH deficiency or Turner syndrome. Pharmacogenomics J. 14, 54-62 (2014)

53. A.J. Whatmore, L. Patel, P.E. Clayton, A pilot study to evaluate gene expression profiles in peripheral blood mononuclear cells from children with GH deficiency and Turner syndrome in response to GH treatment. Clin. Endocrinol. 70, 429-434 (2009)

54. L. Fernández-Pérez, J. Nóvoa, N. Ståhlberg, R. Santana-Farré, M. Boronat, D. Marrero, L. Henríquez-Hernández, G. Norstedt, A. Flores-Morales, The effect of in vivo growth hormone treatment on blood gene expression in adults with growth hormone deficiency reveals potential biomarkers to monitor growth hormone therapy. Clin. Endocrinol. 72, 800-806 (2010) 